\title{
Hevosten Nurmirehut -hanke. Hevosten laiduntaminen viljellyillä laitumilla
}

\author{
Susanna Särkijärvi ${ }^{1)}$, Oiva Niemeläinen ${ }^{2)}$, Riitta Sormunen-Cristian ${ }^{3)}$, Hanna-Elisa Akkanen ${ }^{2)}$, Helena \\ Jansson $^{1)}$ ja Markku Saastamoinen ${ }^{1)}$ \\ ${ }^{1)}$ MTT/Hevostalous, Varsanojantie 63, 32100 Ypäjä, etunimi.sukunimi@mtt.fi \\ ${ }^{2)}$ MTT/Kasvinviljely ja teknologia, E-talo, 31600 Jokioinen, etunimi.sukunimi@mtt.fi \\ ${ }^{3)}$ MTT/Nurmitalouden tutkimus, H-talo, 31600 Jokioinen, etunimi.sukunimi@mtt.fi \\ ${ }^{4)}$ Helsingin yliopisto, kotieläintieteen laitos, PL 28, 00014 Helsingin yliopisto
}

\section{Tiivistelmä}

Laidun on hevosten pääasiallisin rehu kasvukaudella ja usein yksinomainen rehu kivennäisten lisäksi. Laitumen riittävä ja tasainen tuotto laidunkauden eri aikoina helpottaa hevosten ruokintaa. Tuottava laidun on edullista rehua.

Laiduntutkimuksen tärkeimpiä selvitettäviä asioita ovat laitumen sadontuotto ja sen muutokset kasvukauden kuluessa ja laitumen kestävyys. Hevoset syövät laidunkasvit lyhyemmäksi kuin naudat, joten laiduntamisen vaikutus tutkittavien kasvien sadontuottokykyyn ja kestävyyteen on eri eläinlajien välillä erilainen. Laiduntutkimuksilla selvitetään myös kasvilajien ja -seoksien maittavuutta ja laidunkasvien kemiallista koostumusta. Tutkimuksesta saadaan tietoa myös laidunalan mitoituksesta, laidunkauden pituudesta ja hevosten laiduntutkimuksen tekniikasta. Ypäjällä Maa- ja elintarviketalouden tutkimuskeskuksen (MTT) Hevostalouden yksikössä toteutettavat laidunkokeet ovat osa suurempaa Hevosten Nurmirehut -hanketta, joka on MTT:n, Maa- ja metsätalousministeriön (MMM), Helsingin yliopiston ja yritysten rahoittama.

Laidunkoealue kylvettiin Ypäjälle elokuussa 2005. Kokeeseen valittiin koejäseniksi kolme puhdasta kasvilajia (timotei, nurminata ja ruokonata) sekä kolme seosta (timotei-nurminata, timoteiruokonata ja ruokonata-niittynurmikka). Kukin kasvilaji ja -seos kylvettiin kaistoiksi toisiinsa kiinni ja jokainen koejäsen satunnaistettiin neljään kerranteeseen. Koko laidunala oli 240 x 240 metriä. Alue laidunnettiin kolmessa lohkossa siten, että jokaisella lohkolla oli samalla kertaa hevosten laidunnettavana 24 erilaista kasvustokaistaa.

Koeala kärsi perustumisvaikeuksista. Keväällä 2006 tehtiin täydennyskylvöjä, eikä aluetta laidunnettu lainkaan. Vuoden 2007 kevätkasvu korjattiin säilörehuksi ja laidunkoe aloitettiin säilörehuniiton jälkikasvusta heinäkuussa. Laidunkokeeseen otettiin 10 suomenhevostammaa. Hevoset laidunsivat yhdellä lohkolla noin kaksi viikkoa, jonka jälkeen ne siirrettiin seuraavalle lohkolle.

Kultakin laidunlohkolta tehtiin laitumen satomittaukset Haldrup -nurmenkorjuukoneella ennen ja jälkeen laidunnuksen. Lisäksi laitumen määrää arvioitiin ns. nurmikiekko-mittarilla ja kasvuston korkeutta nurmitikulla. Ennen laidunnusta otetuista niittonäytteistä tehtiin laatumääritys NIRS-menetelmällä sekä analysoitiin kemiallinen koostumus. Kasvilajikoostumusta selvitettiin botaanisin analyysein. Eri kasvilajien ja seosten maittavuutta selvitettiin havainnoimalla hevosten syöntikäyttäytymistä.

Sekä laitumen hyväksikäyttöasteen että käyttäytymishavaintojen perusteella maittavimmiksi koejäseniksi osoittautuivat timotei ja ruokonata-niittynurmikkaseos. Nurminata ja sen seos timotein kanssa maistui hevosille heikosti, myöskään ruokonata yksinään ei ollut kovin suosittua. Nurmikasvien satoisuuden ja kestävyyden arviointiin tarvitaan lisää tuloksia. Koe jatkuu kesällä 2008.

Asiasanat: hevonen, laidun, maittavuus, nurminata, ruokonata, timotei, 


\section{Johdanto}

Tuottava laidun on edullista rehua. Laitumen riittävä ja tasainen sato kasvukauden eri aikoina helpottaa hevosten ruokintaa, vähentää työtä ja ruokintakustannuksia. Laidunkausi on Etelä-Suomessa noin 120 130 vuorokautta, hevosilla hieman pitempikin. Hyvin hoidettu laidun pystyisi näin ollen tyydyttämään jopa neljäsosan hevosen vuotuisesta ravinnontarpeesta. Hevosten laiduntaminen on usein kuitenkin laajaperäistä ja laidun mielletään lähinnä hevosen kätevänä ”kesäsäilytyspaikkana”. Laidunkauden huolellinen suunnittelu lisää laiduntamisen tehokkuutta, parantaa rehun hyväksikäyttöä ja kannattavuutta.

Hevosten laiduntutkimusta on tehty erittäin vähän. Ulkomaiset tutkimukset on yleensä tehty erilaisilla kasvilajeilla ja erilaisissa kasvuolosuhteissa, joten tulosten soveltaminen maamme pohjoisiin oloihin on ongelmallista. Kotimaiset laiduntutkimukset naudoilla (Virkajärvi 2004, Virkajärvi ym. 2002) antavat arvokasta tietoa laiduntamiseen ja kasvien menestymiseen, mutta hevosten laiduntaminen poikkeaa melkoisesti lypsylehmien laiduntamisesta. Hevoset muun muassa syövät laidunkasvit lyhyemmäksi kuin naudat, joten laiduntamisen vaikutus kasvien sadontuottokykyyn ja kestävyyteen on erilainen eri eläinlajien välillä. Hevosyrittäjät kaipaavat hevosilla saatua tutkimustietoa ja käytännön kokemuksia.

Kesällä 2007 aloitettiin hevosten laidunkokeet Ypäjällä Maa- ja elintarviketalouden tutkimuskeskuksen (MTT) Hevostalouden yksikössä. Laidunkokeet ovat osa suurempaa Hevosten Nurmirehut -hanketta, joka on MTT:n, Maa- ja metsätalousministeriön (MMM), Helsingin yliopiston (HY) ja yritysten rahoittama. Laiduntutkimusten keskeisenä tavoitteena on selvittää laidunten sadontuotto ja sadontuoton muutokset kasvukauden kuluessa, laidunten kestävyys sekä kasvilajien välisiä maittavuuseroja. Tutkimuksesta saadaan tietoa myös laidunalan mitoituksesta, laidunkauden pituudesta ja hevosten laiduntutkimuksen tekniikasta.

Tässä kirjoituksessa esitetään alustavia tuloksia kesältä 2007. Koska tutkimusosiota ei vielä ole kokonaan analysoitu, kirjoituksessa keskitytään laidunkasvien satoisuuteen ja maittavuuteen. Tutkimus jatkuu kesällä 2008.

\section{Aineisto ja menetelmät}

Hevosten laidunkoetta varten perustettiin Ypäjälle uusi laidun elokuussa 2005. Kokeeseen valittiin kuusi koejäsentä, jotka ovat kolme puhdasta kasvilajia timotei ( $c v$. Tuure), nurminata ( $c v$. Inkeri) ja ruokonata (cv. Retu) sekä kolme seosta timotei-nurminata $(10+15 \mathrm{~kg} / \mathrm{ha})$, timotei-ruokonata $(10+15 \mathrm{~kg} / \mathrm{ha}) \mathrm{ja}$ ruokonata-niittynurmikka (15+10 kg/ha).

Koko laidunala oli 240 x 240 metriä eli 5,76 ha. Kukin kasvilaji/-seos kylvettiin laidunalalla toisiinsa kiinni 10 metriä leveänä ja 240 metriä pitkänä kaistana. Jokainen koejäsen kylvettiin satunnaistetusti neljään kerranteeseen. Alue laidunnettiin kylvösuunnassa kolmessa lohkossa siten, että jokaisella lohkolla oli aina 24 erilaista kasvustokaistaa hevosten valittavissa syötäväkseen.

Vuonna 2007 eli laidunnuskesänä lohko lannoitettiin kolmessa erässä siten, että typpilannoituksen kokonaismääräksi tuli $180 \mathrm{~kg} \mathrm{~N} / \mathrm{ha}$. Typen jako oli $70 \mathrm{~kg}$ N/ha keväällä, $60 \mathrm{~kg} \mathrm{~N} / \mathrm{ha}$ toisella lannoituskerralla ja $50 \mathrm{~kg}$ N/ha kolmannella. Keväällä 2007 toteutettiin rikkakasvien torjuntana Primusruiskutus 0,1-0,15 l/ha + Sito Plus kiinnite (0,1 l/ha). Kevätkasvun laidunnus toteutetaan vuonna 2008.

Hevosten laidunkoe tehtiin kesällä 2007 MTT:n Hevostalouden tutkimusyksikössä Ypäjällä. Tutkimuksessa oli kymmenen MTT/Hevostutkimuksen omistamaa suomenhevostammaa. Tammat olivat iältään 3 - 21 vuotiaita. Hevoset laidunsivat yhdellä lohkolla noin kaksi viikkoa, jonka jälkeen ne siirrettiin seuraavalle lohkolle.

Kasvuston arvioimiseksi laidunlohkolta niitettiin kaista aina ennen kuin hevoset siirrettiin ko. lohkolle ja heti laidunnuksen jälkeen. Niitto tehtiin Haldrup -nurmenkorjuukoneella kylvösuuntaan nähden poikkisuuntaan. Kaistan leveys oli $1,5 \mathrm{~m}$ ja niittokorkeus noin $4 \mathrm{~cm}$. Näin saatiin selville tarjolla olevan laitumen määrä ja laidunnuksen jälkeen jäljellä olevan laitumen määrä. Niittokaistan pinta-ala mitattiin ja alalta niitetyn nurmisadon määrä punnittiin. Koeniiton ja kuiva-ainemäärityksen tulos muunnettiin sitten tuloksissa muotoon kg KA/ha. Lisäksi laidunlohkolta tehtiin mittauksia nurmikiekolla ja nurmitikulla.

Niittonäytteistä tullaan määrittämään koostumus NIR-menetelmällä MTT Kasvintuotannon tutkimuksessa Jokioisilla. MTT-Laboratorioiden Eläinravitsemusryhmässä määritetään kemiallinen koostumus (rehuanalyysi). Lisäksi analysoidaan NDF- ja ADF-kuidut, sokerit, sellulaasiliukoisuus sekä puhtaista kasvilajeista (timotei, nurminata, ruokonata) fruktaanipitoisuus.

Botaaninen analyysi tehtiin jokaiselta lohkolta ennen laiduntamista otetusta niittonäytteestä. Lisäksi tehtiin havaintoja kasvuston peittävyydestä, kasvukauden pituudesta, talvituhoista ja 
hylkylaikuista. Hevosista mitattiin rinnanympärys ja arvioitiin lihavuusaste lohkon vaihtamisen yhteydessä. Lisäksi hevosten syöntikäyttäytymistä havainnoitiin. Tarkoituksena oli selvittää pystyttäisiinkö koejäsenten maittavuutta arvioimaan syöntikäyttäytymisen perusteella.

\section{Tulokset ja tulosten tarkastelu}

Koeala kärsi perustamisvaikeuksista. Myöhäisen kylvöajankohdan vuoksi 2005 talvehtivat kasvit olivat pieniä. Keväällä 2006 kasvustoon tuli suuria roustevaurioita erityisesti ruokonata- ja niittynurmikkakasvustoissa. Vuonna 2006 tehtiin täydennyskylvöjä, jotka kuivan kasvukauden vuoksi perustuivat hitaasti ja epätasaisesti. Vuonna 2006 lohkoa ei laidunnettu vaan tehtiin tasausniittoja ja rikkakasvitorjuntaa. Puhdas ruokonata ja ruokonata/niittynurmikka -koejäsenet olivat vuoden 2007 keväällä vielä niin heikkokasvuisia ja normaalista kasvusta poikkeavia, että koealan kevätkasvu korjattiin säilörehuksi ja heinäksi. Kevätsato niitettiin lohkoilta 1. ja 2. säilörehuksi 15.6. ja 2.7. tehtiin heinää 3. lohkolta.

Koelaitumien sadontuottoa seurattiin kuitenkin ensimmäisen kerran jo alkukesästä 4.6. suoritetulla koeniitolla. Ensimmäisessä niitossa timotei (3083 kg KA/ha) sekä sen seokset ruokonadan (3303 kg $\mathrm{KA} / \mathrm{ha}$ ) ja nurminadan kanssa (3058 kg KA/ha) olivat satoisimmat eli niiden tarjolla olevan laitumen (TOL) määrä oli suurin. Pienin TOL-arvo oli ruokonata-niittynurmikkaseoksella (1319 kg KA/ha) ja ruokonadalla (2038 kg). Nurminadan TOL oli 2731 kg KA/ha. TOL -arvot kuvaavat heinäsadon määrää, eli kokonaistuoresadosta on vähennetty rikkakasvien osuus. Rikkakasveja esiintyi erityisesti ruokonataniittynurmikkaseoksissa (22\%) ja ruokonadassa (7\%).

Laidunkoe aloitettiin säilörehuniiton jälkikasvusta heinäkuussa. Ennen laidunnuksen aloittamista lohkolta 1. tehtiin ensimmäinen koeniitto ja samana päivänä (18.7.) hevoset laskettiin laitumelle. Kuviossa 1. esitetään tarjolla olevan laitumen määrä koejäsenittäin (sisältäen rikkakasvit) eri lohkoilla laidunnuksen alkaessa.

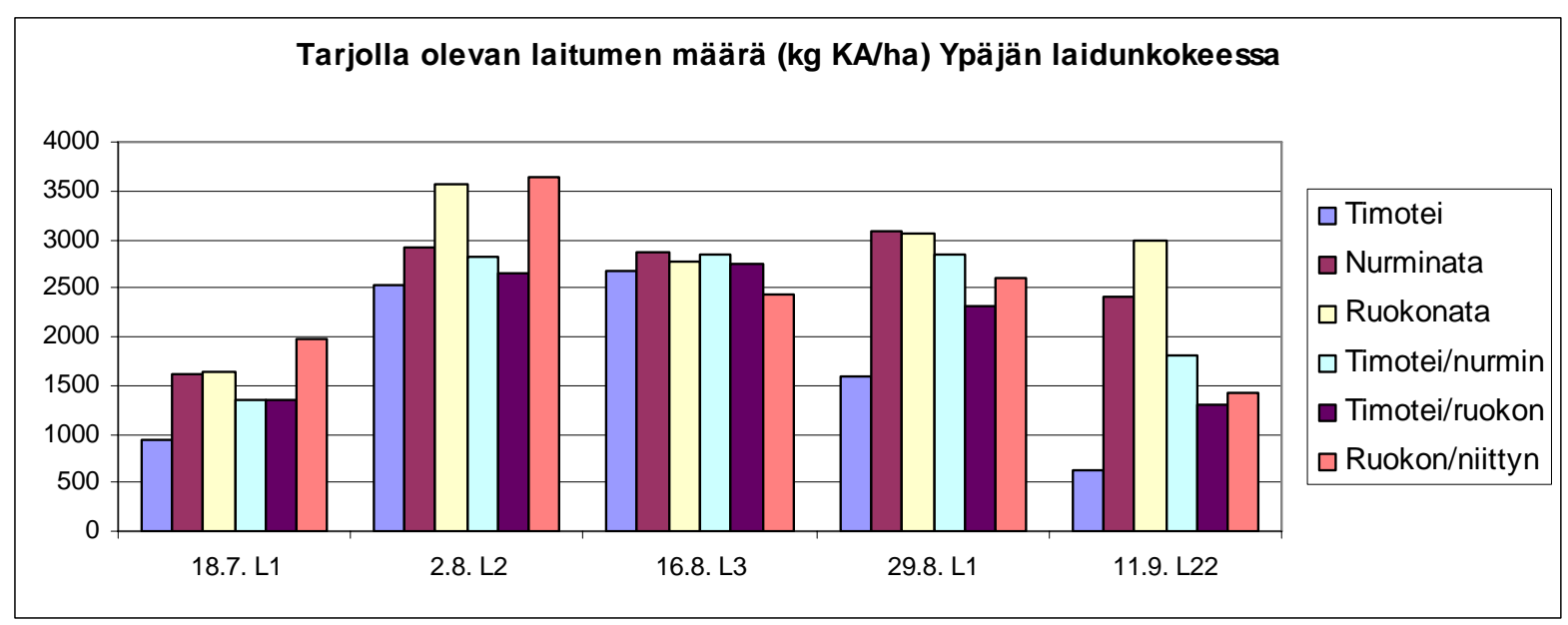

Kuvio 1. Tarjolla olevan laitumen määrä, sisältäen rikkakasvit (kg KA/ha) laidunnuksen alkaessa laidunlohkoilla (L1, L2 ja L3) ensimmäisellä (18.7.-16.8.) ja toisella (29.8.-11.9.) laidunkierrolla. Lohkoilta 1. ja 2. oli edeltävä sato korjattu säilörehuksi 14.6. ja lohkolta 3. heinäksi 2.7.

Kesän ensimmäisessä niitossa satoisimpien timotein ja sen seosten toipuminen säilörehuniitosta laidunkokeen alkuun mennessä (noin kuukausi) oli hidasta. Laidunkokeen alussa selvästi eniten satoa tuotti ruokonata-niittynurmikkaseos, myös puhdas ruokonata ja nurminata olivat toipuneet timoteiseoksia paremmin. Toisessa niitossa ruokonata ja ruokonata-niittynurmikka tuottivat edelleen eniten satoa, jostain syystä ruokonata ei kuitenkaan timoteiseoksena pystynyt vastaaviin satotuloksiin. Lohkolle 3. mentäessä satotulokset koejäsenten välillä tasoittuivat. Kolmoslohkon myöhäisempi ensimmäisen niiton ajankohta näytti vieneen etulyöntiaseman ruokonataseoksilta, joten sen selkeästi parempi satotulos kakkoslohkolla vaikuttaa perustuvan kesäkuun puolenvälin parempaan kasvupotentiaaliin.

Toisella laidunkierrolla erityisesti puhtaan timotein satotulokset laskivat muihin koejäseniin nähden. Parhaiten satoa tuottivat vielä myöhään syksylläkin ruokonata ja nurminata.

Kun tarkastellaan koko koejakson 18.7.- 11.9. satotuloksia, satoisimmaksi tässä loppukesän 
laidunkokeessa osoittautui puhdas ruokonata. Timotei puhtaana kasvilajina oli selvästi heikoin ja jostain syystä muuten satoisa ruokonata ei pystynyt timotein kanssa samoihin satotasoihin kuin yksinään tai niittynurmikan kanssa.

Satotulokset tarkentuvat, kun laskentaan saadaan mukaan tulokset rikkakasvien osuudesta kokonaissadosta. Kuviossa 2. satotulokset lohkolta 3. rikkakasvien osuus huomioituna. Rikkakasveja oli erityisen merkittävässä määrin alunalkaenkin huonosti perustuneissa ruokonadassa ja ruokonataniittynurmikassa. Elokuun niitossa (2.8.2007) ruokonatakoejäsen sisälsi keskimäärin 18\% ja ruokonataniittynurmikkakoejäsen $17 \%$ rikkaruohoja.

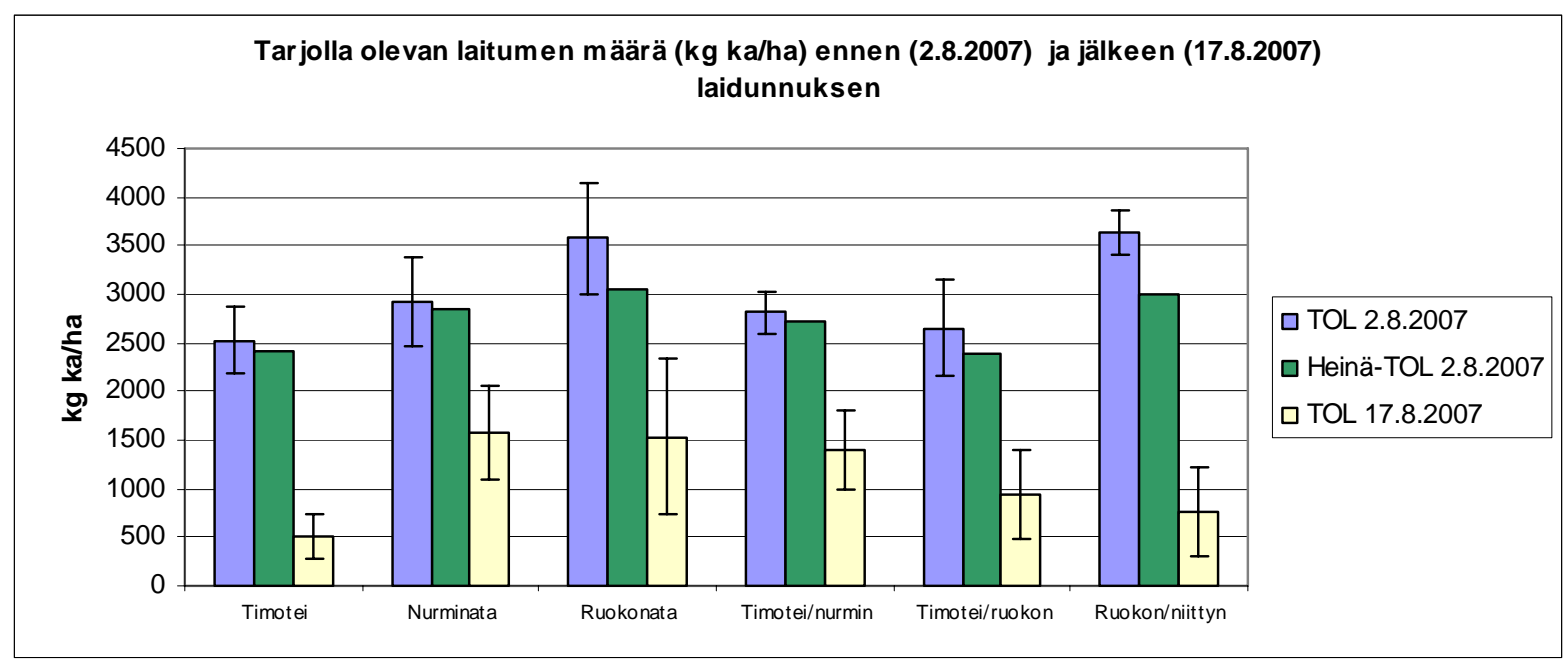

Kuvio 2. Tarjolla olevan laitumen määrä (TOL) kg ka/ha sekä puhtaan heinäkasvuston määrä (HeinäTOL) ennen laidunnusta 2.8.2007 ja laitumen massa kg ka/ha laidunnuksen jälkeen 17.8.2007. Janat kuvaavat keskivirheen suuruutta.

Laitumen hyväksikäyttöprosentti laskettiin ennen laidunnusta ja laidunnuksen jälkeen tehtyjen niittojen satotuloksista. Laskentaan ei mittaustavasta johtuen voitu huomioida laidunnuksen aikaista kasvua. Kuviossa 3. on kuvattu laitumen hyväksikäyttöaste ensimmäisellä laidunkierrolla, toisella laidunkierrolla tulokset olivat vastaavanlaisia.

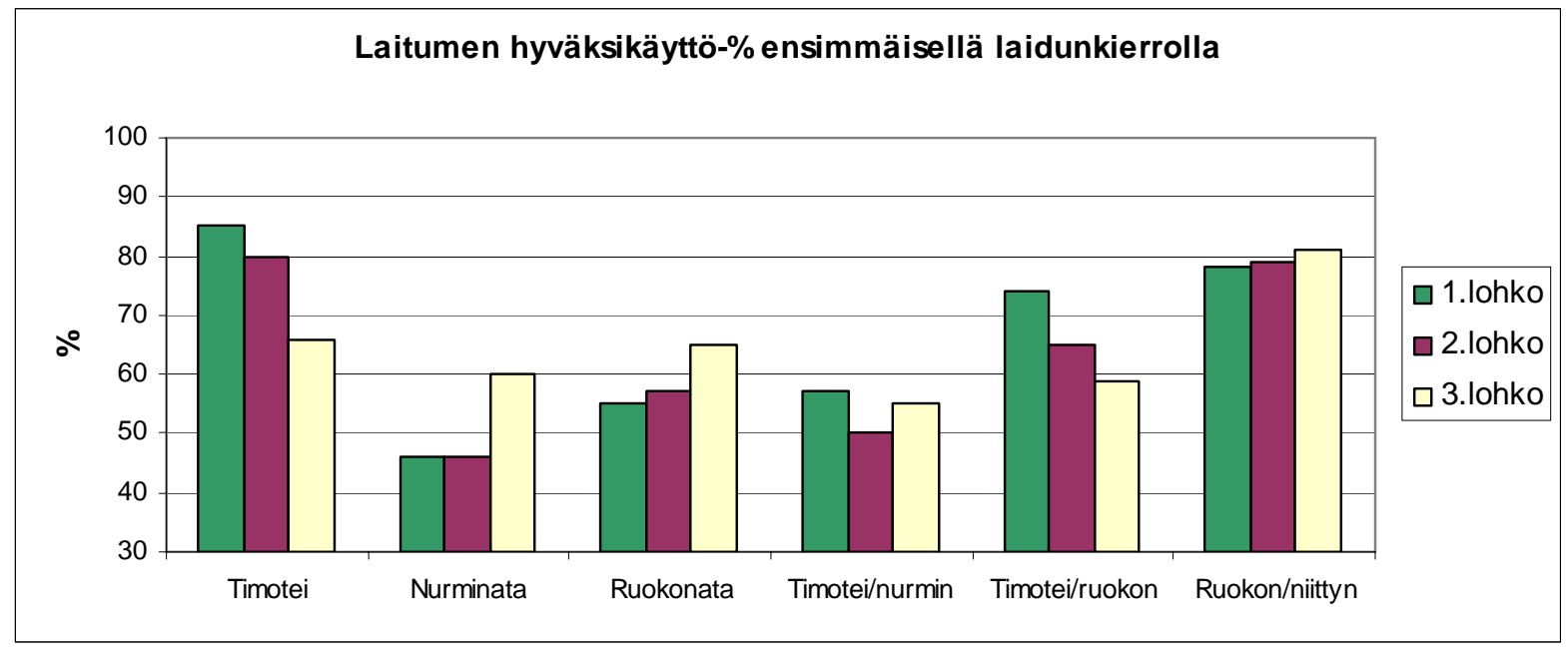

Kuvio 3. Laidunkokeen koejäsenten hyväksikäyttöaste laidunlohkoilla ensimmäisellä (18.7.-16.8.) laidunkierrolla.

Kokonaisuutena paras hyväksikäyttöaste oli ruokonata-niittynurmikkaseoksella, mutta yksittäiset korkeimmat hyväksikäyttöasteet olivat timoteilla. Timotein hevoset söivätkin silminnähden matalimmaksi (Kuva1.). Timotein eri seokset ja ruokonata olivat melko tasavertaisia, mutta heikoin hyväksikäyttöaste oli nurminadalla. Hylkylaikkuja ei muodostunyt vielä toisellakaan saman lohkon laidunnusjaksolla. 
Laidunnuksen aloittaminen säilörehuksi / heinäksi korjatun kasvuston jälkikasvusta ilmeisesti vaikutti vähäiseen hylkylaikkujen määrään.

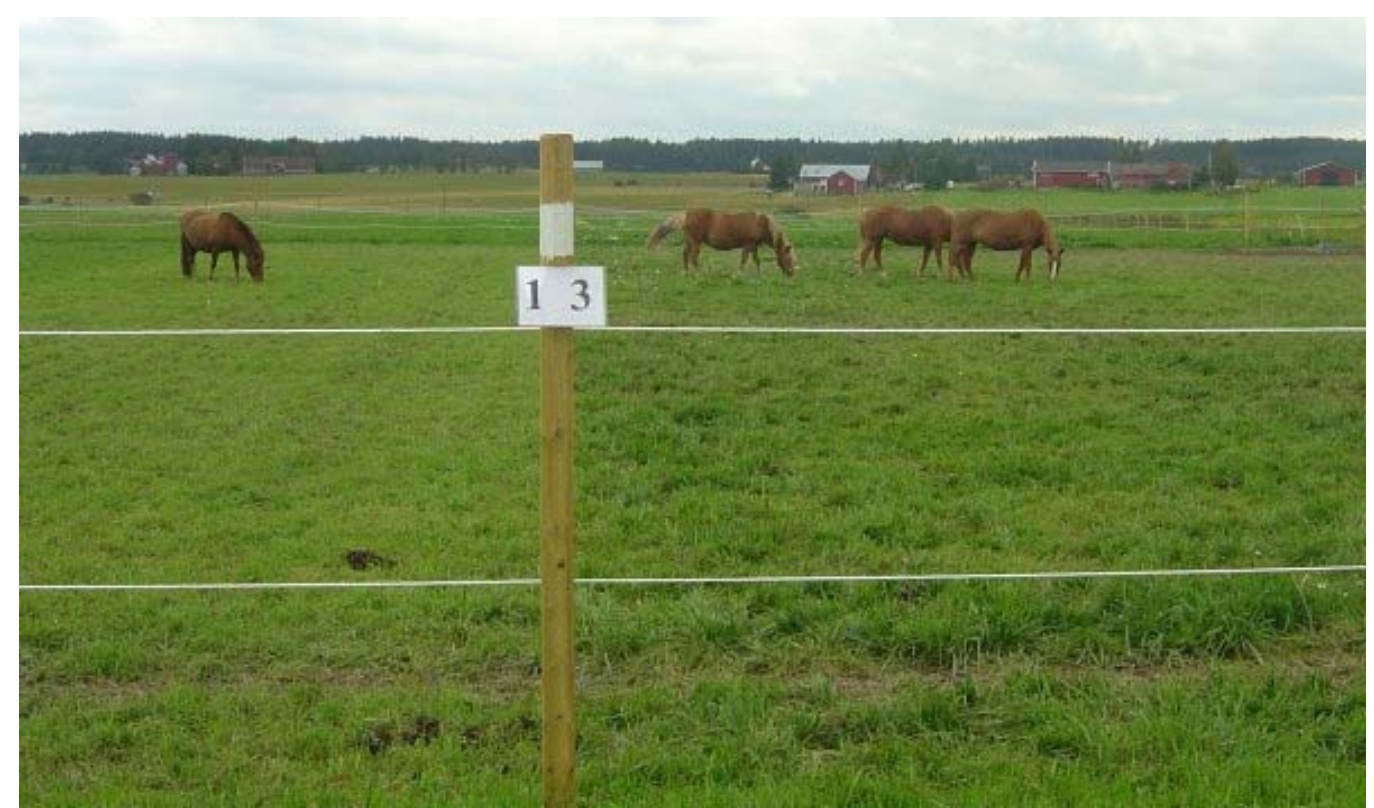

Kuva 1. Koejäsenten välisiä eroja oli laidunnuksen jälkeisessä kasvustossa esimerkiksi timotein ja ruokonadan välillä. Kuva on otettu kaistojen väliltä lohkolta 1. juuri laidunjakson päättyessä 2.8.2007. (Kuva: Oiva Niemeläinen)

Käyttäytymistarkkailun tarkoituksena oli selvittää mitä kasvustoa hevoset mieluiten valitsevat syödäkseen. Aina hevosten siirryttyä uudelle lohkolle aloitettiin käyttäytymistarkkailu viidentenä laidunpäivänä. Havaintoja tehtiin viiden minuutin välein, jolloin merkittiin ylös millä koejäsenellä hevonen on ja syökö se vai ei. Havaintojaksot saattoivat olla eri pituisia ja eri aikaan päivästä, koska oleellista oli tehdä tarkkailua silloin, kun hevoset syövät. Erityisen paahteisina tai sateisina päivinä hevoset saattoivat viettää tuntikausia lähinnä seisten. Syöntihavaintoja tehtiin neljän laidunjakson aikana.

Syömiskäyttäytymishavainnot tukivat satotuloksista laskettuja arvioita eri kasvilajien/-seosten maittavuudesta (Kuvio 3.). Eniten aikaa syömiseen hevoset kuluttivat timotei ja ruokonata-niittynurmikka koejäsenillä ja vähiten nurminata ja timotei-nurminata koejäsenillä. Hevoset viettivät paljon aikaa suojakaistalla, myös syöden, joten tämä alue olikin kokeen loputtua erittäin kulunut.

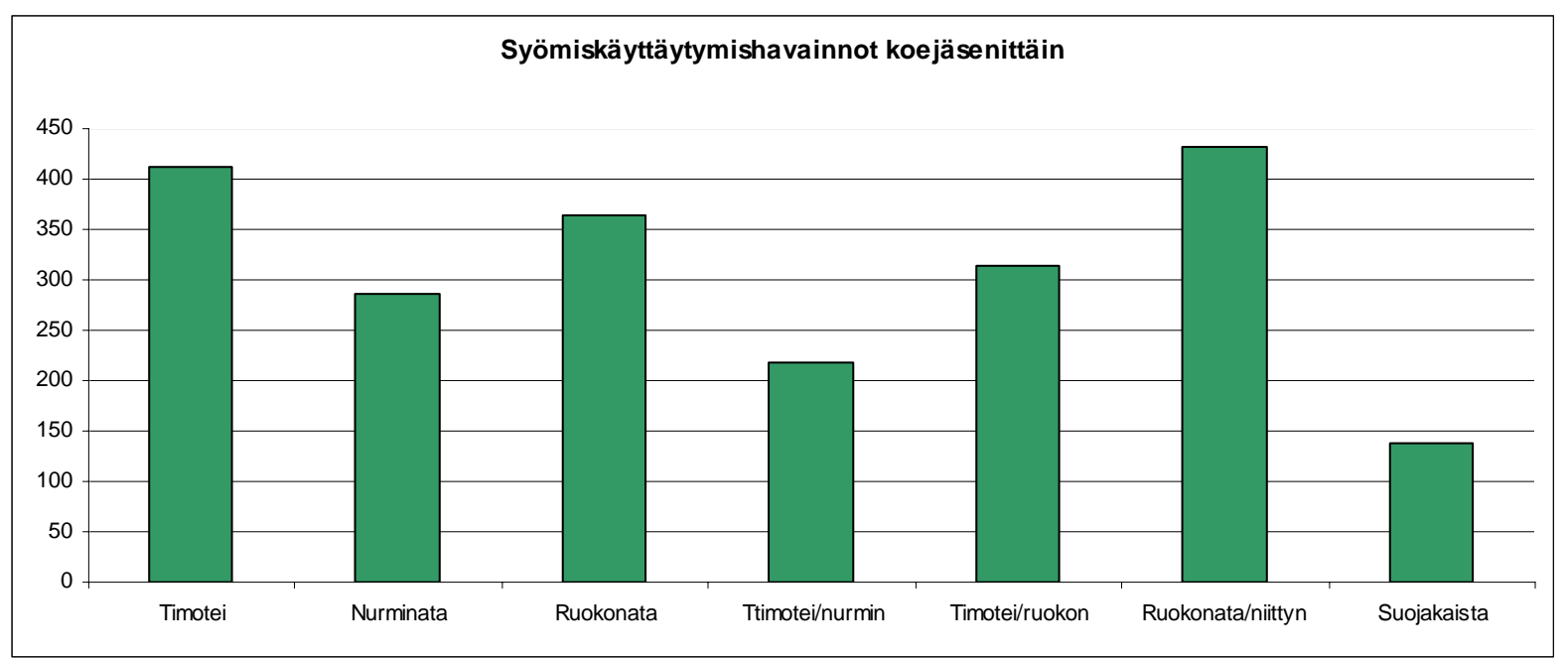

Kuvio 3. Syöntikäyttäytymishavainnot koejäsenillä sekä suojakaistalla, jolla mm. juottopaikka ja portti sijaitsivat. 


\section{Johtopäätökset}

Laidunkokeesta saadaan runsaasti hyvin mielenkiintoista ja käyttökelpoista materiaalia, mutta tulosten tulkinta on haasteellista erityisesti kesän toista saman lohkon laidunkierrosta tarkasteltaessa. Suhteellisen pitkäkestoisen laidunnuksen aikaisen kasvun arviointi jää epäsuoraksi. Eri koejäsenistä jäi sangen erilainen massa laiduntamisen jälkeen ja se vaikuttaa koejäsenen kasvuun ja laatuun sekä kokeen tuloksiin seuraavalla laidunnuskierroksella. Hylkylaikkuja ei muodostunyt vielä toisellakaan saman lohkon laidunnusjaksolla. Käyttäytymishavainnointi näyttäisi olevan luotettava tapa arvioida laidunkasvien maittavuutta. Nopeasti kehittyvän kevätsadon laiduntamisen hallintaa tutkitaan kevätkesällä 2008.

\section{Kirjallisuus}

Virkajärvi, P. 2004. Growth and utilization of timothy - meadow fescue pastures. Ph.D. Dissertation. University of Helsinki. Department of Applied Biology. 56 p.

Virkajärvi, P., Sairanen, A., Nousiainen, J.I. \& Khalili, H. 2002. Effect of herbage allowance on pasture utilization, regrowth and milk yield on dairy cows in early, mid and late season. Animal Feed Science and Technology 97: 23-40. 